\title{
The role of magnetic resonance imaging in the management of schistosomal myeloradiculopathy
}

\author{
O papel da ressonância magnética no manejo da mielorradiculopatia esquistossomótica \\ Leandro Tavares Lucato
}

Neuroradiologist, Instituto de Radiologia do Hospital das Clínicas da Faculdade de Medicina da USP, Fleury Medicina Diagnóstica, São Paulo SP, Brazil.

Correspondence Leandro Tavares Lucato Avenida Doutor Enéas de Carvalho Aguiar $255 / 3^{\circ}$ andar 05403-001 São Paulo SP - Brasil E-mail:ltlucato@uol.com.br

Conflict of interest There is no conflict of interest to declare.

Received 26 November 2011 Accepted 05 December 2011
Schistosomiasis is a chronic, parasitic disease caused by blood flukes (trematode worms) of the genus Schistosoma ${ }^{1}$. First reports of what most likely correspond to the disease were found in Egyptian medical papyri, and eggs of the worms were found in mummies ${ }^{2,3}$. In spite of being recognized more than 30 centuries ago, recent data indicate that more than 207 million people are infected worldwide, with an estimate of 700 million people at risk in endemic countries ${ }^{1}$. However, even outside endemic areas, its importance has been rising in recent years, since today's highly mobile, interdependent, and interconnected world provides myriad opportunities for its spread.

Involvement of the central nervous system (neuroschistosomiasis) is caused by infection with S. mansoni, S. haematobium, or S. japonicum. Schistosomal myeloradiculopathy (SMR), usually related to $S$. mansoni infection, is the most frequently recognized presentation of neuroschistosomiasis, although it is still considered underdiagnosed in endemic areas ${ }^{4}$.

Diagnosis of SMR is usually presumptive, relying on a positive epidemiology and pertinent neurological picture (spinal cord and/or nerve root involvement, most often the lower portions of the cord and cauda equina). It is also necessary to demonstrate the schistosomal infection and to exclude other causes of myelopathy.

There are undoubtedly a couple of issues related to demonstration of the infection: parasite load is small in SMR compared to other forms of the disease, causing difficulties in obtaining positive stool samples (rectal biopsies present higher sensitivity, however); serological tests lack specificity especially in endemic areas; and immunodiagnostic tests in the cerebrospinal fluid (CSF), although promising, need validation before their widespread use . $^{4}$

In this scenario, magnetic resonance imaging (MRI) demonstrates high sensitivity but unfortunately not high specificity. However, MRI is a relevant tool, not only helping to increase the likelihood of SMR in a given patient but also in the potential recognition of other diseases mimicking it. Most commonly, one can find enlargement of the lower spinal cord and/or cauda equina roots, presenting hyperintensity in T2-weighted images and variable post-contrast enhancement ${ }^{5,6}$. This constellation of findings supports the diagnosis when associated with pertinent clinical and epidemiological data, especially when an elevated eosinophil count is present in the CSF analysis.

Patterns of gadolinium enhancement related to SMR, which can coexist in a single patient and even change during the course of the disease, include intramedullary nodules, lesions in the cord surface and enhancing thickened nerve roots ${ }^{5}$. In a small sample (three patients), a more specific pattern was described, characterized by an 'arborized' appearance derived from central linear enhancement surrounded by multiple enhancing punctate nodules ${ }^{7}$. Taken together, these studies can advocate for the diagnosis of SMR when multiple enhancing intramedullary nodules are seen in the lower cord.

Vidal et al. ${ }^{8}$, in the present issue of Arquivos de Neuro-Psiquiatria, draw attention to a less common MRI picture in SMR. The presence of extensive cord compromise, manifested by T2-hyperintensity involving the whole spinal cord or its thoracic and lumbar regions, was appreciated in 10 out of 12 patients with MRI abnormalities; diffuse enhancement was found in 
eight of them, somewhat heterogeneous but distinct to the above described patterns.

Their findings certainly deserve some reflection on possible factors influencing the involvement of high spinal cord segments and the development of diffuse enhancement. The most important mechanism to underscore is undoubtedly the immune response of the host to the presence of parasite eggs, probably directed towards a vasculitis mediated by eosinophils, immune complexes, or both; instead of the most frequently observed granulomatous reaction. The authors speculate that this is at least in part related to the fact that patients come from a recent endemic area. Therefore, their exposition to the parasite is also recent, leading to a more exuberant immune response.

Since neuroschistosomiasis is a spectral disorder that can be understood more accurately as a continuum, it includes less common presentations, such as the ones described by Vidal et al. Prospective, longitudinal studies including more patients with distinct backgrounds are encouraged in order to address some of the issues presented and to advance in the knowledge of such an important disease.

\section{References}

1. Schistosomiasis. Fact sheet $N^{\circ} 115$. [Internet] [acessed 2011 Nov 20]. Available from: http://www.who.int/mediacentre/factsheets/fs115/ en/index.html\#.

2. Ruffer MA. Note on the presence of "Bilharzia haematobia" in Egyptian mummies of the twentieth dynasty. Br Med J 1910;1:16.2.

3. Brier B. Infectious diseases in ancient Egypt. Infect Dis Clin North Am 2004;18:17-27.

4. Ferrari TC, Moreira PR. Neuroschistosomiasis: clinical symptoms and pathogenesis. Lancet Neurol 2011;10:853-864.

5. Saleem S, Belal Al, el-Ghandour NM. Spinal cord schistosomiasis: MR imaging appearance with surgical and pathologic correlation. AJNR Am J Neuroradiol 2005;26:1646-1654.
6. Peregrino AJ, Puglia PM, Bacheschi LA, et al. Diagnosis of schistosomiasis of the spinal cord: contribution of magnetic resonance imaging and electroneuromyography. Arq Neuropsiquiatr 2002;60:597-602.

7. Sanelli PC, Lev MH, Gonzalez RG, Schaefer PW. Unique linear and nodular MR enhancement pattern in schistosomiasis of the central nervous system: report of three patients. AJR Am J Roentgenol 2001;177:1471-1474.

8. Vidal CHF, Ferreira MLB, Azevedo-Filho HRC, Gurgel FV, BrainerLima AM. Extensive spinal cord involvement in magnetic resonance imaging evaluation on schistosomal myelitis. Arq Neuropsiquiatr 2012;70:210-213. 